\title{
Performance evaluation of foxtail amaranth (Amaranthus gangeticus) and GIFT tilapia grown in a recirculating aquaponics system
}

\section{MOHAMMAD TANVEER AND M. SIVAKUMAR}

Received : 28.08.2017; Revised : 11.09.2017; Accepted : 27.09.2017

See end of the Paper for authors' affiliation

Correspondence to :

MOHAMMAD TANVEER

Department of Aquacultural Engineering, College of Fisheries Engineering, Tamil Nadu Fisheries University, NAGAPATTINAM (T.N.) INDIA Email : nobletanveer@gmail. $\underline{\text { com }}$
-ABSTRACT : This paper deals with the development and performance evaluation of aquaponics system. In the present study GIFT tilapia fingerlings and foxtail amaranth (Amaranthus gangeticus) seeds were procured and grown in fish culture tank and plant bed, respectively in aquaponics unit. This study demonstrates and evaluated the growth of GIFT tilapia and foxtail amaranth (Amaranthus gangeticus) grown in aquaponics system and normal culture system. The fish fingerlings of average weight $0.70 \mathrm{~g}$ were procured from a fish farmer. The fish weight was recorded in aquaponics and glass tank and was found to be 83.20 and $78.10 \mathrm{~g}$, respectively after 160 days of culture. Plant height observed in aquaponics system and normal culture system which was recorded as $18.10 \mathrm{~cm}$ and $20.20 \mathrm{~cm}$, respectively. The recirculation flow rate in aquaponics was maintained $0.43 \mathrm{~L} /$ throughout the culture and the average biofiltration efficacy was found to 23 per cent. Fish were fed at the rate of 12 per cent of body weight with commercially available feed.

- KEY WORDS : Aquaponics system, GIFT tilapia, Foxtail Amaranth (Amaranthus gangeticus); Recirculation flow rate

- HOW TO CITE THIS PAPER : Tanveer, Mohammad and Sivakumar, M. (2017). Performance evaluation of foxtail amaranth (Amaranthus gangeticus) and GIFT tilapia grown in a recirculating aquaponics system. Internat. J. Agric. Engg., 10(2) : 631-637, DOI: 10.15740/HAS/IJAE/10.2/631637. 